\title{
I 067 MR assessment of long term pulmonary arterial morphology following surgical ligation of systemic to pulmonary arterial shunts: visualising a potential risk
}

\author{
Shankar Sridharan*, Mark de Leval, Marina Hughes, Wendy Norman, \\ Catherine Bull and Andrew Taylor
}

Address: Great Ormond St Hospital for Children, London, UK

* Corresponding author

from I th Annual SCMR Scientific Sessions

Los Angeles, CA, USA. I-3 February 2008

Published: 22 October 2008

Journal of Cardiovascular Magnetic Resonance 2008, I0(Suppl I):AI92 doi:I0.II86/I532-429X-I0-SI-AI 92

This abstract is available from: http://jcmr-online.com/content/I0/SI/AI92

(C) 2008 Sridharan et al; licensee BioMed Central Ltd.

\section{Introduction}

Formation of a Blalock-Taussig (BT) shunt to establish a secure source of pulmonary blood flow is the first stage of palliation for a significant proportion of children born with congenital heart disease. With further palliative or corrective surgery, ligation rather than surgical division of a previously-formed BT shunt has been the preferred surgical strategy. We hypothesise that ligation rather than division of a shunt carries a risk of iatrogenic vascular constraint with respect to the pulmonary arteries, producing distortion with somatic growth.

\section{Purpose}

As an initial approach to assess this, using Cardiac Magnetic Resonance (MR) Imaging, we studied branch pulmonary artery (PA) anatomy and pulmonary artery blood flow in a homogenous cohort of patients with similar primary cardiac anatomy, haemodynamics and surgical course.

\section{Methods}

We retrospectively reviewed cardiac magnetic resonance (MR) imaging studies and hospital records of all patients with Tetralogy of Fallot who had undergone surgical takedown of a Blalock-Taussig Shunt between January 1987 and January 1992, (a 15-20 year period of follow-up from the present date). Non-breath-hold, FLASH gradient echo phase-contrast MR sequences was used to measure flow in the pulmonary trunk and the non-stenosed PA's. Anatom- ical features were assessed with MR angiographic and bSSFP images. MR scans were reviewed by experienced personnel blinded to clinical details and the surgical history for the presence of: 1) angiographic PA distortion (tenting/kinking), 2) presence of PA hypoplasia, 3) abnormalities of distal pulmonary vascular arborisation.

\section{Results}

Forty-five patients underwent corrective surgery for Tetralogy of Fallot during the study period, had been subsequently studied with MR imaging, and had available operative records. Of this group, 30 patients underwent primary repair, and 15 patients were known to have had a previous BT shunt that was taken down at the time of complete repair. The median time from the takedown of the BT shunt to assessment by MR imaging was 16.0 years (range to 10.4 to 19.2 years). Twelve patients had their BT shunts ligated and one patient had their shunt surgically divided. The surgical method was not specified for 2 patients. Asymmetry of branch PA anatomy and flow was evident in every patient, and unilateral abnormalities correlated with the side of the previous BT shunt.

Specific tenting and kinking related to the position of the BT shunt was evident in 5/12 patients after undergoing BT ligation. Absence of this kinking was noted in the single patient undergoing surgical division of the shunt. 


\section{Conclusion}

Surgical placement of a BT has long been associated with PA distortion. This limited review suggests that simple ligation at the time of take-down of this shunt, may be associated with accentuated distortion of PA morphology and growth, but is not consistently so. Further assessment of this phenomenon is needed, with particular attention to the cohort of patients with functionally univentricular hearts and Fontan-type circulation, who require low pulmonary pressures for effective pulmonary flow.

Publish with Bio Med Central and every scientist can read your work free of charge

"BioMed Central will be the most significant development for disseminating the results of biomedical research in our lifetime. " Sir Paul Nurse, Cancer Research UK

Your research papers will be:

- available free of charge to the entire biomedical community

- peer reviewed and published immediately upon acceptance

- cited in PubMed and archived on PubMed Central

- yours - you keep the copyright

Submit your manuscript here:

http://www.biomedcentral.com/info/publishing_adv.asp 